\title{
Maintenance Intravenous Fluids in Acutely III Patients
}

TO THE EDITOR: The recommendation by Moritz and Ayus (Oct. 1 issue) $)^{1}$ of $0.9 \%$ normal saline as default maintenance fluid in acutely ill patients fails to consider the increased risk of hypernatremia and volume expansion that may occur. Both complications may be potentially as damaging as the hyponatremia that the authors seek to avoid. ${ }^{2,3}$ Hypernatremia accompanies ongoing hypotonic losses, including from sweat and the urea-induced diuresis associated with nutritional supplementation, and the hypertonic gain of $0.9 \%$ saline with added potassium. By definition, maintenance represents an amount and content of fluid needed to maintain a steady state. The emergence of iatrogenic hyponatremia or hypernatremia with any one-size-fits-all prescription indicates a miscalculation of maintenance fluids for a given patient. It is necessary to first define and achieve the steady state desired, to measure or estimate all input and output volumes and electrolyte content, and to recalculate at regular intervals. Urinary sodium excretion, potassium excretion, and flow rate allow for simple calculations of a positive or negative electrolyte-free water clearance and isotonic loss. The best guideline to prevent severe complications would be an algorithm for constructing a therapeutic plan for an individual patient.

Julian L. Seifter, M.D.

Brigham and Women's Hospital

Boston, MA

jseifter@partners.org

No potential conflict of interest relevant to this letter was reported.

1. Moritz ML, Ayus JC. Maintenance intravenous fluids in acutely ill patients. N Engl J Med 2015;373:1350-60.

2. Lindner G, Funk GC, Schwarz C, et al. Hypernatremia in the critically ill is an independent risk factor for mortality. Am J Kidney Dis 2007;50:952-7.

3. Kovesdy CP, Lott EH, Lu JL, et al. Hyponatremia, hypernatremia, and mortality in patients with chronic kidney disease with and without congestive heart failure. Circulation 2012;125:677-84.

DOI: 10.1056/NEJMc1513887

TO THE EDITOR: The review by Moritz and Ayus raises certain issues that may be debated. Fluid tonicity is determined by the total concentration of osmotically active ions, and not solely sodium. Similarly, the desired composition of maintenance intravenous fluids should include not just sodium chloride but adequate dextrose and potassium to prevent starvation ketosis and hypokalemia, respectively, especially for surgical patients during prolonged fasting. ${ }^{1,2}$ However, adding concentrated potassium chloride to isotonic saline risks misadministration ${ }^{3}$ and renders the latter hypertonic. The sodium load with cumulative $0.9 \%$ saline infusion may compound hypervolemic risk among susceptible patients with cardiac or renal disease. The use of chloriderich solutions is also strongly associated with increased morbidity in critically ill and surgical cohorts. ${ }^{4,5}$ Balanced electrolyte solutions contain more physiologic chloride content and are nearly isotonic but have insufficient potassium for maintenance use. Premixed solutions with dextrose $5 \%$ and potassium chloride with varying saline content help address these dilemmas but are limited by their hypotonic tendencies. An individualized approach to maintenance-fluid selection should be based on the above considerations, bearing imperfections of all available solutions. But default maintenance with $0.9 \%$ saline is certainly not ideal.

\section{Horng-Ruey Chua, M.Med.}

National University Hospital

Singapore, Singapore

horng_ruey_chua@nuhs.edu.sg

Dr. Chua reports receiving research sponsorship from Baxter, in the form of filters for continuous renal-replacement therapy for an investigator-initiated study. No other potential conflict of interest relevant to this letter was reported.

1. Vather R, Bissett I. Management of prolonged post-operative ileus: evidence-based recommendations. ANZ J Surg 2013;83: 319-24.

2. Intravenous fluid therapy in adults in hospital. London: National Institute for Health and Care Excellence (NICE), December 2013.

3. Joint Commision. WHO Collaborating Center for Patient Safety's nine life-saving Patient Safety Solutions. Jt Comm J Qual Patient Saf 2007;33:427-62.

4. Yunos NM, Bellomo R, Hegarty C, Story D, Ho L, Bailey M. Association between a chloride-liberal vs chloride-restrictive intravenous fluid administration strategy and kidney injury in critically ill adults. JAMA 2012;308:1566-72.

5. Shaw AD, Bagshaw SM, Goldstein SL, et al. Major complications, mortality, and resource utilization after open abdominal surgery: 0.9\% saline compared to Plasma-Lyte. Ann Surg 2012; 255:821-9.

DOI: $10.1056 / N E J M c 1513887$

TO THE EDITOR: Moritz and Ayus in their review of maintenance fluids in acutely ill patients do 
not mention one viable alternative - no maintenance fluid. In our medical intensive care unit, we do not routinely prescribe standing intravenous fluids and would challenge the concept of an "almost ubiquitous need for intravenous fluids in acutely ill patients." If a patient is volumedepleted and presumed to be volume-responsive, we provide fluid boluses with reevaluations before additional doses. Often, between tube feedings and intravenous medications, our patients receive liters a day of fluid without starting traditional maintenance fluid.

I agree with the authors' assertion that hypotonic fluid often leads to hyponatremia but would add that isotonic fluid $(0.9 \%$ saline) may lead to hyperchloremic acidosis and may contribute to renal failure. ${ }^{1,2}$ Furthermore, several studies now provide evidence that a positive fluid balance in critically ill patients with sepsis or the acute respiratory distress syndrome correlates with increased mortality. ${ }^{3,4}$ On the basis of such studies, I would advocate that not giving maintenance intravenous fluid is a viable alternative for acutely ill patients.

Lindsay Lief, M.D.

Weill Cornell Medical College

New York, NY

liw9021@med.cornell.edu

No potential conflict of interest relevant to this letter was reported.

1. Yunos NM, Bellomo R, Glassford N, Sutcliffe H, Lam Q, Bailey M. Chloride-liberal vs. chloride-restrictive intravenous fluid administration and acute kidney injury: an extended analysis. Intensive Care Med 2015;41:257-64.

2. Yunos NM, Bellomo R, Story D, Kellum J. Bench-to-bedside review: chloride in critical illness. Crit Care 2010;14:226.

3. Sakr Y, Vincent JL, Reinhart K, et al. High tidal volume and positive fluid balance are associated with worse outcome in acute lung injury. Chest 2005;128:3098-108.

4. Boyd JH, Forbes J, Nakada TA, Walley KR, Russell JA. Fluid resuscitation in septic shock: a positive fluid balance and elevated central venous pressure are associated with increased mortality. Crit Care Med 2011;39:259-65.

DOI: 10.1056/NEJMc1513887

TO THE EDITOR: The review by Moritz and Ayus highlights the importance of avoiding iatrogenic hyponatremia, particularly in central nervous system (CNS) disease, to avoid osmotic edema. Appropriate selection of electrolyte composition, tonicity, and the rate of administration of intravenous fluids is key to reducing the risk of potential complications. Although we agree with the general management recommendations made in this review, we disagree with the suggestion that " $5 \%$ dextrose in isotonic solution" (see Fig. 2 of the article, available at NEJM.org) should be used as first-line fluid therapy for CNS disease and particularly for stroke (see Case 2 of the article).

Stress hyperglycemia is common after acute CNS injury. We argue that dextrose should be avoided in any patient with a stroke, ischemic or hemorrhagic, who is hyperglycemic because it could lead to a poor outcome. ${ }^{1,2}$ In addition, hyperglycemia has been consistently linked to an increased risk of hemorrhage among patients with stroke who are treated with tissue plasminogen activator. ${ }^{3}$ We suggest that the addition of dextrose in acutely ill patients follows guidelines for glycemic control that were outlined previously in the Journal. ${ }^{4}$

Axel Petzold, M.D., Ph.D.

University College London Institute of Neurology

London, United Kingdom

a.petzold@ucl.ac.uk

Giuseppe Citerio, M.D.

University of Milan-Bicocca

Milan, Italy

Stephan A. Mayer, M.D.

Icahn School of Medicine at Mount Sinai

New York, NY

No potential conflict of interest relevant to this letter was reported.

1. Fogelholm R, Murros K, Rissanen A, Avikainen S. Admission blood glucose and short term survival in primary intracerebral haemorrhage: a population based study. J Neurol Neurosurg Psychiatry 2005;76:349-53.

2. Seners P, Turc G, Oppenheim C, Baron JC. Incidence, causes and predictors of neurological deterioration occurring within $24 \mathrm{~h}$ following acute ischaemic stroke: a systematic review with pathophysiological implications. J Neurol Neurosurg Psychiatry 2015;86:87-94.

3. Zhang J, Yang Y, Sun H, Xing Y. Hemorrhagic transformation after cerebral infarction: current concepts and challenges. Ann Transl Med 2014;2:81-7.

4. Kavanagh BP, McCowen KC. Glycemic control in the ICU. N Engl J Med 2010;363:2540-6.

DOI: 10.1056/NEJMc1513887

THE AUTHORS REPLY: Seifter and Chua raise the concern that $0.9 \%$ saline, with or without potassium, risks the development of hypernatremia and fluid overload. As we stated in the article, "Isotonic fluids could also result in hypernatremia if there is a renal concentrating defect or if there are large extrarenal free-water losses. Any 
type of intravenous fluid can result in fluid overload if administered in excessive quantities (for example, in patients with end-stage renal disease or heart failure in whom both sodium excretion and water excretion are impaired)." Isotonic fluids are otherwise incapable of producing hypernatremia or fluid overload, because a normally functioning kidney can generate free water by excreting a hypertonic urine. ${ }^{1}$ This is a physiologic response, as we have described previously in healthy ambulatory children, ${ }^{2}$ and this response explains why hyponatremia (rather than fluid overload) develops in patients with a syndrome of inappropriate secretion of antidiuretic hormone (SIADH)-like states in response to intravenous fluids. The subclinical volume expansion associated with an excess of arginine vasopressin triggers hemodynamic regulatory mechanisms to maintain plasma volume at the expense of plasm sodium, which is in part due to a pressure-natriuresis mechanism and a secondary release of natriuretic peptides. $^{3}$

As was stated in our article, in more than 15 randomized, prospective trials involving more than 2000 patients, isotonic fluids were not associated with an increased risk of hypernatremia or fluid overload. In Table 1 and Figure 2 of our article, we outline the disease states that require special considerations in fluid management, and we provide an algorithm for adjusting the intravenous-fluid rate and composition in order to prevent fluid overload and hypernatremia.

Chua and Lief raise an additional concern regarding the high chloride concentration in $0.9 \%$ saline. After the publication of our article, a randomized study by Young et al. compared $0.9 \%$ saline with a balanced electrolyte solution in more than 2000 critically ill patients. ${ }^{4}$ They found no significant between-group differences in complications such as acute kidney injury, a need for mechanical ventilation, electrolyte disturbances, and death.

Lief questions the needs for maintenance fluids in critically ill patients owing to the risk of fluid overload. As stated in Figure 2 of our article, maintenance fluids are indicated only after the resuscitation phase of fluid therapy, and we recommend fluid restriction to $25 \mathrm{ml}$ per hour for oligoanuric states in order to prevent fluid overload.

Petzold et al. correctly point out the dangers of hyperglycemia in patients with stroke. To the best of our knowledge, $5 \%$ dextrose in maintenance fluids is not associated with hyperglycemia in the absence of diabetes.

Michael L. Moritz, M.D.

Children's Hospital of Pittsburgh

Pittsburgh, PA

moritzml@upmc.edu

Juan C. Ayus, M.D.

Renal Consultants of Houston

Houston, TX

Since publication of their article, the authors report no further potential conflict of interest.

1. Andersen LJ, Norsk P, Johansen LB, Christensen P, Engstrom T, Bie P. Osmoregulatory control of renal sodium excretion after sodium loading in humans. Am J Physiol 1998;275:R1833-42.

2. Moritz ML. Urine sodium composition in ambulatory healthy children: hypotonic or isotonic? Pediatr Nephrol 2008; 23:955-7.

3. Cogan E, Debieve MF, Pepersack T, Abramow M. Natriuresis and atrial natriuretic factor secretion during inappropriate antidiuresis. Am J Med 1988;84:409-18.

4. Young P, Bailey M, Beasley R, et al. Effect of a buffered crystalloid solution vs saline on acute kidney injury among patients in the intensive care unit: the SPLIT randomized clinical trial. JAMA 2015;314:1701-10.

DOI: 10.1056/NEJMc1513887

\section{In-Flight Medical Emergencies}

TO THE EDITOR: Nable et al. (Sept. 3 issue) ${ }^{1}$ did not mention that acute allergic reactions may occur on airplanes, probably triggered by a food, especially peanuts (commonly served on flights), a drug, or in rare cases, an insect bite or sting. Food allergies among children increased by approximately 50\% between 1997 and 2011. ${ }^{2}$

The first-line treatment for anaphylaxis, a severe and often life-threatening reaction, is prompt administration of epinephrine and a hospital visit. ${ }^{3,4}$ Because the need for treatment is often immediate (especially in persons with hypotension or airway compromise) and death may occur before transfer to a hospital, many states have passed laws to ensure that epinephrine is available in schools and other public buildings. Clearly, 